3. Lin CM, Gill RG. Direct and indirect allograft recognition: pathways dictating graft rejection mechanisms. Curr Opin Organ Transpl. 2016;21:40-4.

4. Hwang B, Bryers J, Mulligan MS. Potential role of exosome-based allorecognition pathways involved in lung transplant rejection. J Thorac Cardiovasc Surg. 2021; 161:e129-34.
5. Robbins PD, Morelli AE. Regulation of immune responses by extracellular vesicles. Nat Rev Immunol. 2014;14:195-208.

6. Gunasekaran M, Sharma M, Hachem R, Bremner R, Smith MA, Mohanakumar T. Circulating exosomes with distinct properties during chronic lung allograft rejection. J Immunol. 2018;200:2535-41.
See Article page e129.

\section{Commentary: It's time for exosomes to get the limelight in lung transplant}

\author{
Michael K. Y. Hsin, FRCS, CTh, ${ }^{\mathrm{a}}$ and \\ Mingyao Liu, MD ${ }^{\mathrm{b}}$
}

Lung transplant (LTx) recipients have the worst outcomes among all those receiving solid organ transplants, with 50\% of recipients developing chronic lung allograft dysfunction (CLAD). ${ }^{1}$ Understanding the immunology of LTx is an important step toward improving these outcomes. In this issue of the Journal, Hwang and colleagues ${ }^{2}$ reviewed the potential role of exosome-based allorecognition pathways in LTx rejection, which seems to be a missing link between the innate and adaptive immunity and the development of CLAD.

The term exosome was first used by Johnstone and colleagues $^{3}$ in 1987 to describe sacs filled with smaller vesicles in maturing reticulocytes. Previously, exosomes had been regarded as a waste disposal mechanism. They are now understood to play important intercellular communication roles in normal physiology, such as reproduction and development, ${ }^{4}$ immune modulation, ${ }^{5}$ skin pigmentation, ${ }^{6}$ and modulation of host defenses against pathogens. ${ }^{7}$ In pathologic states, exosomes have been shown to be involved in neurologic diseases, ${ }^{8}$ cardiomyocyte hypertrophy, ${ }^{9}$ and cancer cell motility. ${ }^{10}$

In the review by Hwang and colleagues, ${ }^{2}$ important preclinical models of skin and heart transplant were cited to show alloreactive T-cell responses are initiated by donor

From the a Department of Cardiothoracic Surgery, Queen Mary Hospital, Hong Kong; and ${ }^{\mathrm{b}}$ Latner Thoracic Surgery Research Laboratories, Toronto General Hospital Research Institute, University Health Network, Toronto, Ontario, Canada.

Disclosures: The authors reported no conflicts of interest.

The Journal policy requires editors and reviewers to disclose conflicts of interest and to decline handling or reviewing manuscripts for which they may have a conflict of interest. The editors and reviewers of this article have no conflicts of interest.

Received for publication April 26, 2020; revisions received April 26, 2020; accepted for publication April 29, 2020; available ahead of print May 15, 2020.

Address for reprints: Michael K. Y. Hsin, FRCS, CTh, Department of Cardiothoracic Surgery, Queen Mary Hospital, Room 308, New Clinical Building, Hong Kong (E-mail: mkhsin@hotmail.com).

J Thorac Cardiovasc Surg 2021;161:e136-7

$0022-5223 / \$ 36.00$

Copyright (c) 2020 by The American Association for Thoracic Surgery

https://doi.org/10.1016/j.jtcvs.2020.04.155
Check for updates

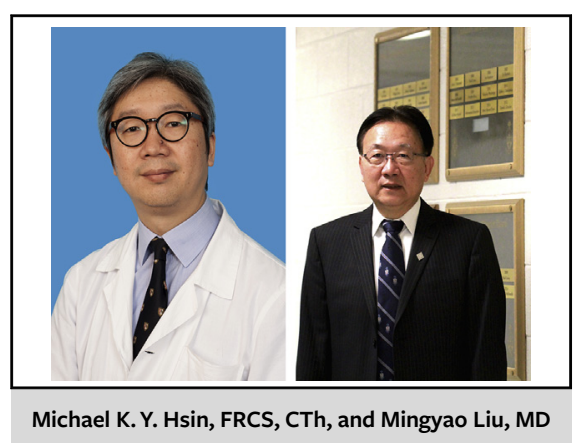

CENTRAL MESSAGE

Exosome-based allorecognition

pathways seem to be a missing

link between innate and adaptive

immunity and the development

of CLAD. Exosomes might be

potential biomarkers and targets

of therapy for CLAD.

exosomes, instead of passenger leucocytes, as previously accepted. ${ }^{11-13}$ New concepts, such as allo-exo-antigen, its production, and recognition pathways (direct, indirect, semidirect, and innate allo-exo-recognition), were introduced. These immunologic terms could be new to many thoracic and cardiovascular surgeons. However, understanding these new concepts could help us to develop new knowledge in the clinical LTx setting.

Exosomes have been implicated in the development of LTx rejection. The RNA profiles of exosomes extracted from bronchoalveolar lavage fluid from LTx recipients with acute rejection showed an inflammatory response, with signals of both innate and adaptive immune activation. ${ }^{14}$ The serum and bronchoalveolar lavage fluid of LTx recipients with acute rejection or bronchiolitis obliterans syndrome, the exosomes contained donor human leukocyte antigens HLA and self-antigens (SAgs). These were not seen in stable LTx recipients. ${ }^{15}$ Circulating exosomes 
isolated from LTx recipients with a diagnosis of respiratory viral infections contained lung SAgs, viral antigens, and $20 \mathrm{~S}$ proteasome, and when these exosomes were given to mice, the mice elicited immune responses to lung SAgs that resulted in the development of CLAD. ${ }^{16}$

In LTx recipients, exosomes containing SAgs and collagen $\mathrm{V}$ were detected in the serum 3 months before clinical acute rejection and 6 months before the clinical development of bronchiolitis obliterans syndrome, ${ }^{15}$ supporting their potential role as biomarkers of chronic rejection, although this requires further validation. Another line of investigation proposed by the Arizona group is blockage of exosome formation and release by pharmacologic agents during ex vivo lung perfusion to improve LTx outcomes. ${ }^{17}$

In the past decade, an explosion has occurred in exosome-related research across many fields. As our knowledge of the mechanism of alloimmune responses mediated by exosomes accumulate, a whole new area of clinical translation will likely open up, leading to improved outcomes for LTx recipients.

\section{References}

1. Grossman E, Shilling R. Bronciolitis obliterans in lung transplantation: the good, the bad, and the future. Transl Res. 2009;153:153-65.

2. Hwang B, Bryers J, Mulligan M. Potential role of exosome-based allorecognition pathways involved in lung transplant rejection. J Thorac Cardiovasc Surg. 2021; 161:e129-34.

3. Johnstone RM, Adam M, Hammond JR, Orr L, Turbide C. Vesicle formation during reticulocyte maturation. association of plasma membrane activities with released vesicles (exosomes). J Biol Chem. 1987;262:9412-20.
4. Sullivan R, Saez F, Girouard J, Frenette G. Role of exosomes in sperm maturation during the transit along the male reproductive tract. Blood Cells Mol Dis. 2005; 35:1-10.

5. Robbins PD, Morelli AE. Regulation of immune responses by extracellular vesicles. Nat Rev Immunol. 2014;14:195-208.

6. Cicero AL, Delevoye C, Gilles-Marsens F, Loew D, Dingli F, Guéré C, et al. Exosomes released by keratinocytes modulate melanocyte pigmentation. Nat Commun. 2015;6:7506.

7. Schorey JS, Harding CV. Extracellular vesicles and infectious diseases: new complexity to an old story. J Clin Invest. 2016;126:1181-9.

8. Stuendl A, Kunadt M, Kruse N, Bartels C, Moebius W, Danzer KM, et al. Induction of $\alpha$-synuclein aggregate formation by CSF exosomes from patients with Parkinson's disease and dementia with Lewy bodies. Brain. 2016;139: 481-94.

9. Bang C, Batkai S, Dangwal S, Gupta SK, Foinquinos A, Holzmann A, et al. Cardiac fibroblast-derived microRNA passenger strand-enriched exosomes mediate cardiomyocyte hypertrophy. J Clin Invest. 2014;124:2136-46.

10. Shimoda M, Principe S, Jackson HW, Luga V, Fang H, Molyneux SD, et al. Loss of the Timp gene family is sufficient for the acquisition of the CAF-like cell state. Nat Cell Biol. 2014;16:889-901.

11. Elkins WL, Guttmann RD. Pathogenesis of a local graft versus host reaction: immunogenicity of circulating host leukocytes. Science. 1968;159:1250-1.

12. Liu Q, Rojas-Canales DM, Divito SJ, Shufesky WJ, Stolz DB, Erdos G, et al Donor dendritic cell-derived exosomes promote allograft-targeting immune response. J Clin Invest. 2016;126:2805-20.

13. Marino J, Babiker-Mohamed MH, Crosby-Bertorini P, Paster JT, LeGuern C, Germana $\mathrm{S}$, et al. Donor exosomes rather than passenger leukocytes initiate alloreactive T cell responses after transplantation. Sci Immunol. 2016;1:aaf8759.

14. Gregson AL, Hoji A, Injean P, Poynter ST, Briones C, Palchevskiy V, et al Altered exosomal RNA profiles in bronchoalveolar lavage from lung transplants with acute rejection. Am J Respir Crit Care Med. 2015;192:1490-503.

15. Gunasekaran M, Xu Z, Nayak DK, Sharma M, Hachem R, Walia R, et al. Donorderived exosomes with lung self-antigens in human lung allograft rejection. Am J Transplant. 2017; 17:474-84.

16. Gunasekaran M, Bansal S, Ravichandran R, Sharma M, Perincheri S, Rodriguez F, et al. Respiratory viral infection in lung transplantation induces exosomes that trigger chronic rejection. J Heart Lung Transplant. 2020;39:379-88.

17. Ravichandran R, Bansal S, Rahman M, Sharma M, Liu W, Bharat A, et al. The role of donor-derived exosomes in lung allograft rejection. Hum Immunol. 2019;80:588-94 